\title{
The Significance of Circulating Cell-Free DNA Markers in Chronic Hepatitis B Patients with Hepatocellular Carcinoma
}

\author{
Alkistis Papatheodoridi ${ }^{1,2,+}$, Nikolaos Karakousis ${ }^{2,3,+} \mathbb{D}$, Panagiotis Lembessis ${ }^{2}$, Antonios Chatzigeorgiou ${ }^{2,4, *}$ \\ and George V. Papatheodoridis ${ }^{3, *(D)}$ \\ 1 Department of Clinical Therapeutics, "Alexandra" General Hospital of Athens, Medical School of National, \\ Kapodistrian University of Athens, 11528 Athens, Greece; alkistispapath@gmail.com \\ 2 Department of Physiology, Medical School of National, Kapodistrian University of Athens, \\ 11527 Athens, Greece; karak2727@gmail.com (N.K.); lembessis@hotmail.com (P.L.) \\ 3 Department of Gastroenterology, General Hospital of Athens "Laiko", Medical School of National, \\ Kapodistrian University of Athens, 11527 Athens, Greece \\ 4 Institute for Clinical Chemistry and Laboratory Medicine, University Clinic Carl Gustav Carus, Technische \\ Universität Dresden, 01307 Dresden, Germany \\ * Correspondence: achatzig@med.uoa.gr (A.C.); gepapath@med.uoa.gr (G.V.P.); Tel.: +30-2107462623 (A.C.); \\ $+30-2132061115$ (G.V.P.) \\ + These authors contributed equally.
}

\section{check for}

updates

Citation: Papatheodoridi, A.; Karakousis, N.; Lembessis, P.; Chatzigeorgiou, A.; Papatheodoridis, G.V. The Significance of Circulating Cell-Free DNA Markers in Chronic Hepatitis B Patients with Hepatocellular Carcinoma. Pathogens 2021, 10, 1524. https://doi.org/ 10.3390 / pathogens 10111524

Academic Editors: Tara Patricia Hurst and Lemonia Skoura

Received: 16 September 2021

Accepted: 19 November 2021

Published: 22 November 2021

Publisher's Note: MDPI stays neutral with regard to jurisdictional claims in published maps and institutional affiliations.

Copyright: (c) 2021 by the authors. Licensee MDPI, Basel, Switzerland. This article is an open access article distributed under the terms and conditions of the Creative Commons Attribution (CC BY) license (https:/ / creativecommons.org/licenses/by/ $4.0 /)$.
Abstract: (1) Background: Hepatocellular carcinoma (HCC) is the most serious complication of chronic hepatitis B (CHB). Recently, the detection of circulating cell-free (cf) DNA and nucleosomes has found numerous applications in oncology. This study aimed to examine the levels of serum cfDNA markers and nucleosomes in CHB patients with and without HCC and assess their potential association with HCC patients' survival. (2) Methods: Nineteen patients with CHB and HCC and 38 matched patients with $\mathrm{CHB}$ without cancer development during 5 years of antiviral therapy were included. Stored serum samples were analyzed for cfDNA species, including the cfDNA concentration and levels of Alu115, Alu247, and nucleosomes. DNA integrity was expressed as the Alu247/Alu115 ratio. (3) Results: Compared to controls, HCC patients had higher median Alu247 levels (64.2 vs. 23.2 genomic equivalent, $p=0.004)$ and DNA integrity (1.0 vs. $0.7, p<0.001)$ and a trend for a higher median cfDNA concentration ( $36.0 \mathrm{vs.} 19.5 \mathrm{ng} / \mathrm{mL}, p=0.064)$. Increased DNA integrity (Alu247/Alu115 > 1) was associated with an increased risk of death during the first year after HCC diagnosis ( $p=0.016)$. (4) Conclusions: Levels of Alu247 and DNA integrity in serum cfDNA are elevated in CHB patients with HCC, whereas increased DNA integrity seems to be associated with a worse short-term prognosis in this setting.

Keywords: hepatitis B; hepatocellular carcinoma; cell-free DNA; nucleosomes; DNA integrity

\section{Introduction}

Hepatocellular carcinoma (HCC) is currently classified as the most common type of liver cancer [1]. Worldwide, most HCC cases are associated with chronic hepatitis $\mathrm{B}(\mathrm{CHB})$ and/or cirrhosis of any etiology [1]. Patients with $\mathrm{CHB}$ usually receive longterm oral antiviral therapy, achieving virological remission in almost all compliant cases and improving liver histological lesions and their overall outcome [2-4]. However, HCC may develop even in effectively treated patients and remains the only factor that affects liver-related mortality [5,6]. Therefore, the identification of HCC risk factors is of great importance in this setting.

Cell-free DNA (cfDNA) is free-floating genetic material found in the plasma, serum, and other body fluids [7]. Recently, cfDNA detection has found numerous applications in oncology, including early diagnosis, detection of minimal residual disease, evaluation of treatment response, and resistance [7-10]. Non-long terminal repeats, such as Alu elements, are overrepresented in cfDNA [11] and are often used for distinguishing necrotic cell death 
induced by tumorigenesis and apoptosis [12]. During apoptosis, shorter fragments of DNA are released in the circulation, allowing us to detect short Alu elements of 115 pair bases (bp) [13]. However, in cancer, the rate of necrotic death increases, resulting in increased concentration of longer fragments, such as Alu elements of $245 \mathrm{bp}$, in cfDNA [12-15]. Thus, the parameter of DNA integrity, defined as the ratio of longer fragments to shorter fragments, is usually elevated in cancer patients $[14,15]$. Elevated levels of total circulating nucleosomes have also been recorded in cancer patients because of increased cell turnover [16,17]. Nucleosomes consist of small DNA chains (147 bp) wrapped around a histone octamer and are suspected to carry information for the generation of new metastases in cancer; therefore, their concentration is frequently elevated in the plasma and serum of cancer patients $[16,17]$.

The aim of this study was to compare the serum levels of these biomarkers in CHB patients with and without HCC and to assess their potential associations with the survival of patients with HCC.

\section{Results}

\subsection{Patient Characteristics}

The main baseline characteristics of the 19 HCC cases and $38 \mathrm{CHB}$ controls are presented in Table 1. The two groups did not differ significantly in most baseline characteristics. Compared to CHB controls, HCC cases had normal alanine aminotransferase (ALT) less frequently $(2 / 19$ or $13.3 \%$ vs. $15 / 38$ or $44.1 \%, p=0.037)$. The HCC risk according to the PAGE-B score was high or moderate in all HCC cases and CHB controls. The Barcelona Clinic Liver Cancer (BCLC) stage was A in 2 (10.5\%), B in 15 (78.9\%), and C in 2 (10.5\%) patients with HCC. All patients with BCLC stage A underwent surgical resection, all patients with BCLC stage B were treated with transarterial chemoembolization, and all patients with BCLC stage C were treated with sorafenib.

Table 1. Baseline characteristics of HBeAg-negative chronic hepatitis B patients with and without hepatocellular carcinoma (HCC cases and CHB controls).

\begin{tabular}{|c|c|c|c|}
\hline Patient Characteristic & $\begin{array}{l}\text { HCC Cases } \\
(\mathrm{N}=19)\end{array}$ & $\begin{array}{l}\text { CHB Controls } \\
(\mathbf{N}=38)\end{array}$ & $p$ \\
\hline Age, years & $71(15)$ & $71(14)$ & 0.63 \\
\hline Male gender, $\mathrm{n}(\%)$ & $17(89.5)$ & $35(92.1)$ & 0.74 \\
\hline Body mass index, $\mathrm{kg} / \mathrm{m}^{2}$ & $25.1(3.2)$ & $25.6(5.2)$ & 0.52 \\
\hline $\begin{array}{c}\text { Alcohol use, } \mathrm{n}(\%) \\
\text { None/mild }(<20 \mathrm{~g} / 24 \mathrm{~h}) \\
\text { Moderate } \\
\text { Abuse (past or present) }\end{array}$ & $\begin{array}{l}1(66.7) \\
3(16.7) \\
3(16.7)\end{array}$ & $\begin{array}{c}26(70.3) \\
8(21.6) \\
3(8.1)\end{array}$ & 0.61 \\
\hline $\begin{array}{c}\text { Smoking habits, } \mathrm{n}(\%) \\
\text { Never } \\
\text { Past } \\
\text { Current }\end{array}$ & $\begin{array}{l}13(72.2) \\
2(11.1) \\
3(16.7)\end{array}$ & $\begin{array}{l}20(54.1) \\
8(21.6) \\
9(24.3)\end{array}$ & 0.42 \\
\hline Diabetes mellitus, n (\%) & $1(5.6)$ & $9(23.7)$ & 0.10 \\
\hline Normal ALT ( $\leq 40 \mathrm{IU} / \mathrm{L}), \mathrm{n}(\%)$ & $2(13.3)$ & $15(44.1)$ & 0.04 \\
\hline ALT in cases with elevated ALT, IU/L & $134(173)$ & $112(141)$ & 0.47 \\
\hline Platelet counts, $\times 10^{3} / \mathrm{mm}^{3}$ & $143(63.5)$ & $151(61.3)$ & 0.48 \\
\hline $\begin{array}{l}\text { Platelet groups, } \mathrm{n}(\%) \\
\geq 200,000 / \mathrm{mm}^{3} \\
100,000-199,999 / \mathrm{mm}^{3} \\
<100,000 / \mathrm{mm}^{3}\end{array}$ & $\begin{array}{c}3(17.6) \\
12(70.6) \\
2(11.8)\end{array}$ & $\begin{array}{c}3(7.9) \\
27(71.1) \\
8(21.1)\end{array}$ & 0.45 \\
\hline
\end{tabular}


Table 1. Cont.

\begin{tabular}{|c|c|c|c|}
\hline Patient Characteristic & $\begin{array}{c}\text { HCC Cases } \\
(\mathbf{N}=19)\end{array}$ & $\begin{array}{c}\text { CHB Controls } \\
(\mathrm{N}=38)\end{array}$ & $p$ \\
\hline Undetectable HBV DNA, n (\%) & $9(47.4)$ & $20(52.6)$ & 0.71 \\
\hline Cirrhosis, n (\%) & $10(52.6)$ & $14(36.8)$ & 0.26 \\
\hline \multicolumn{4}{|l|}{ For patients with cirrhosis } \\
\hline Albumin, g/dL & $3.6(0.2)$ & $3.6(0.5)$ & 0.23 \\
\hline Bilirubin, $\mathrm{mg} / \mathrm{dL}$ & $1.0(0.2)$ & $1.1(0.3)$ & 0.19 \\
\hline International normalized ratio & $1.2(0.2)$ & $1.1(0.2)$ & 0.26 \\
\hline Child-Pugh score & $5(0)$ & $5(0)$ & 0.84 \\
\hline PAGE-B score & $19.7 \pm 3.2$ & $20.5 \pm 3.0$ & 0.38 \\
\hline \multicolumn{4}{|l|}{ HCC risk by PAGE-B score, n (\%) } \\
\hline Low $($ PAGE-B score $<10)$ & 0 & 0 & \multirow{3}{*}{1.00} \\
\hline Medium (PAGE-B score 10-17) & $4(21)$ & $8(20.5)$ & \\
\hline High (PAGE-B score > 17) & $15(79)$ & $31(79.5)$ & \\
\hline \multicolumn{4}{|l|}{ Antiviral therapy, n (\%) } \\
\hline Entecavir & $5(26.3)$ & $7(18.4)$ & \\
\hline Tenofovir disoproxil fumarate & $14(73.7)$ & $31(81.6)$ & \\
\hline
\end{tabular}

Quantitative variables are expressed as median values (interquartile range).

\subsection{Circulating cfDNA Species and cfDNA Integrity}

Circulating cfDNA species in HCC cases and CHB controls are presented in Table 2. The median cfDNA concentration tended to be higher in HCC cases than CHB controls, but the difference did not reach statistical significance (36.0 (94.0) vs. $19.5(27.3) \mathrm{ng} / \mathrm{mL}$, $p=0.064)$. The median Alu115 serum levels did not differ significantly between HCC cases and CHB controls (50.1 (68.2) vs. 33.9 (33), $p=0.139$ ). However, the median levels of Alu247 were significantly higher in the HCC cases compared to CHB controls (64.2 (67.9) vs. $23.2(29.7), p=0.004$ ) (Figure 1a). In addition, DNA integrity (Alu247/Alu115 ratio) was significantly higher in the group of HCC cases compared to CHB controls (1.0 (0.7) vs. 0.7 (0.3), $p<0.001$ ) (Figure 1b). Similarly, increased DNA integrity (Alu247/Alu115 >1) was observed significantly more frequently in HCC cases than CHB controls $(57.9 \%$ vs. $15.8 \%, p=0.001)$. The levels of nucleosomes were similar between the two groups.

Table 2. Distinct circulating cell-free DNA (cfDNA) species in HBeAg-negative chronic hepatitis B patients with and without hepatocellular carcinoma (HCC cases and CHB controls).

\begin{tabular}{|c|c|c|c|}
\hline Circulating cfDNA Species & HCC Cases $(\mathrm{N}=19)$ & CHB Controls $(\mathrm{N}=37)$ & $p$ \\
\hline cfDNA concentration, $\mathrm{ng} / \mathrm{mL}$ & $36.0(94.0)$ & $19.5(27.3)$ & 0.06 \\
\hline Alu115 levels, GE & $50.1(68.2)$ & $33.9(33.0)$ & 0.14 \\
\hline Alu247 levels, GE & $64.2(67.9)$ & $23.2(29.7)$ & 0.01 \\
\hline Alu247/Alu115 ratio (DNA integrity) & $1.0(0.7)$ & $0.7(0.3)$ & $<0.001$ \\
\hline Alu247/Alu115 ratio >1, n (\%) & $11(57.9)$ & $6(15.8)$ & 0.01 \\
\hline Total nucleosomes, ng/mL & $25.2(33.1)$ & $26.4(40.1)$ & 0.78 \\
\hline
\end{tabular}

GE: genomic equivalents. Quantitative variables are expressed as median values (interquartile range).

Since the proportion of increased DNA integrity differed significantly between HCC cases and CHB controls and was also associated with one-year mortality of HCC cases, as shown below, the associations between increased DNA integrity and other patient ${ }^{\prime}$ characteristics were determined (Table 3). There was no association between increased DNA integrity with any patient characteristic, except for a trend for probably a random association with platelet groups, as increased DNA integrity was observed relatively more 
frequently in patients with moderate platelet counts $\left(100,000-199,999 / \mathrm{mm}^{3}: 14 / 39\right.$ or $\left.36 \%\right)$ than in patients with high $\left(\geq 200,00 / \mathrm{mm}^{3}: 1 / 6\right.$ or $\left.17 \%\right)$ or low $\left(<100,00 / \mathrm{mm}^{3}: 0 / 10\right)$ platelet counts $(p=0.06)$. The proportion of increased DNA integrity was higher in patients with HCC $(11 / 19$ or $58 \%)$ vs. non-HCC patients with cirrhosis $(1 / 14$ or $7 \%, p=0.004)$ or without cirrhosis $(5 / 24$ or $21 \%, p=0.025)$ and similar between cirrhotic and non-cirrhotic patients with HCC $(7 / 10$ or $70 \%$ vs. $4 / 9$ or $44 \%, p=0.370)$ or without HCC $(1 / 14$ or $7 \%$ vs. $5 / 24$ or $21 \%, p=0.383)$. In patients with HCC, the median alfa-fetoprotein levels did not differ between cases with and without increased DNA integrity (340 (751) vs. 286 (2061) ng/mL, $p=0.717)$.

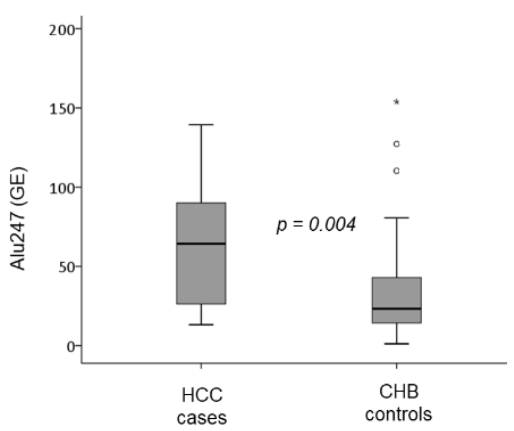

(a)

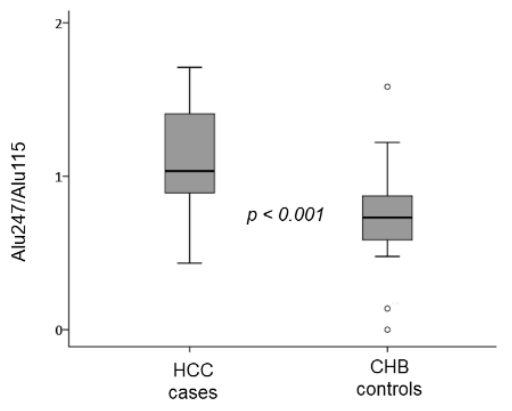

(b)

Figure 1. Levels of Alu247 (a) and the Alu 247/115 ratio (b) in HBeAg-negative chronic hepatitis B patients (CHB) with (HCC cases, $n=19$ ) and without (Controls, $n=18$ ) development of hepatocellular carcinoma (HCC). Box and whisker plots show median, 25th-75th percentile, and minimum-maximum values. Outliers are shown by "0" or "**".

Table 3. Baseline characteristics of $57 \mathrm{HBeAg-negative} \mathrm{chronic} \mathrm{hepatitis} \mathrm{B} \mathrm{patients} \mathrm{with} \mathrm{or} \mathrm{without} \mathrm{hepatocellular} \mathrm{carcinoma}$ in relation to the presence of increased DNA integrity (Alu247/Alu115 ratio >1).

\begin{tabular}{|c|c|c|c|}
\hline \multirow{2}{*}{ Patient Characteristic } & \multicolumn{2}{|c|}{ Increased DNA Integrity } & \multirow[t]{2}{*}{$p$} \\
\hline & Yes $(\mathrm{N}=17)$ & No $(N=40)$ & \\
\hline Age, years & $71(15)$ & $70(14)$ & 0.35 \\
\hline Male gender, n (\%) & $14(82.4)$ & $38(95)$ & 0.12 \\
\hline Body mass index, $\mathrm{kg} / \mathrm{m}^{2}$ & $25.0(3.7)$ & $25.6(5.4)(3.7)$ & 0.24 \\
\hline $\begin{array}{c}\text { Alcohol use, } \mathrm{n}(\%) \\
\text { None/Mild }(<20 \mathrm{~g} / 24 \mathrm{~h}) \\
\text { Moderate } \\
\text { Abuse (past or present) }\end{array}$ & $\begin{array}{l}10(66.7) \\
5(33.3) \\
0(0)\end{array}$ & $\begin{array}{l}28(70) \\
6(15) \\
6(15)\end{array}$ & 0.13 \\
\hline $\begin{array}{c}\text { Smoking habits, n (\%) } \\
\text { Never } \\
\text { Past } \\
\text { Current } \\
\end{array}$ & $\begin{array}{c}11(73.3) \\
1(6.7) \\
3(20)\end{array}$ & $\begin{array}{l}22(55) \\
9(22.5) \\
9(22.5)\end{array}$ & 0.34 \\
\hline Diabetes mellitus, $\mathrm{n}(\%)$ & $2(12.5)$ & $8(20)$ & 0.51 \\
\hline Normal ALT ( $\leq 40 \mathrm{IU} / \mathrm{L}), \mathrm{n}(\%)$ & $5(41.7)$ & $12(32.4)$ & 0.56 \\
\hline ALT in cases with elevated ALT, IU/L & $62(115)$ & $59(123)$ & 0.92 \\
\hline Platelet counts, $\times 10^{3} / \mathrm{mm}^{3}$ & $145(47)$ & $151(85)$ & 0.62 \\
\hline $\begin{array}{c}\text { Platelet groups, } \mathrm{n}(\%) \\
\geq 200,000 / \mathrm{mm}^{3} \\
100,000-199,999 / \mathrm{mm}^{3} \\
<100,000 / \mathrm{mm}^{3}\end{array}$ & $\begin{array}{c}1(6.7) \\
14(93.3) \\
0(0)\end{array}$ & $\begin{array}{l}5(12.5) \\
25(62.5) \\
10(25)\end{array}$ & 0.06 \\
\hline Undetectable HBV DNA, n (\%) & $11(64.7)$ & $18(45)$ & 0.17 \\
\hline Cirrhosis, n (\%) & $8(47.1)$ & $16(40)$ & 0.62 \\
\hline PAGE-B score & $19.7(2.4)$ & $20.6(3.2)$ & 0.45 \\
\hline $\begin{array}{l}\text { HCC risk by PAGE-B score, } \mathrm{n}(\%) \\
\text { Medium (PAGE-B score } 10-17) \\
\text { High (PAGE-B score }>17 \text { ) }\end{array}$ & $\begin{array}{c}3(21.4) \\
11(78.6)\end{array}$ & $\begin{array}{c}8(20) \\
32(80)\end{array}$ & 0.91 \\
\hline
\end{tabular}




\subsection{Survival}

The median overall survival for HCC cases was 523 (821) days. Univariate Cox regression analysis for circulating cfDNA species and patients' baseline characteristics including HCC BCLC stage did not reveal any factor to be significantly associated with HCC cases' overall survival (Table 4). However, subgroup analyses for patients' one-year mortality revealed that only DNA integrity was associated with an increased risk of death during the first year after HCC diagnosis (hazard ratio (HR: 2.46, 95\% confidence interval (CI): $1.15-5.28 ; p=0.020$ ) (Table 4). Particularly, compared to patients without an increased Alu247 / Alu115 ratio (>1) at baseline, those with an increased ratio were at increased risk of dying during the first year after HCC diagnosis (log-rank, $p=0.016$ ) (Figure 2). DNA integrity remained an independent risk factor for patients' one-year mortality, even after adjustment for HCC BCLC stage (HR: 2.19, 95\% CI: 1.02-4.71; $p=0.043$ ).

Table 4. Cox regression analyses for associations of patients' baseline characteristics and distinct circulating cell-free DNA (cfDNA) species with overall and one-year mortality in $19 \mathrm{HBeAg-negative} \mathrm{chronic} \mathrm{hepatitis} \mathrm{B} \mathrm{patients} \mathrm{with} \mathrm{hepatocellu-}$ lar carcinoma.

\begin{tabular}{|c|c|c|c|c|c|c|}
\hline & \multicolumn{3}{|c|}{ Overall Mortality } & \multicolumn{3}{|c|}{ One-Year Mortality } \\
\hline & HR & $95 \% \mathrm{CI}$ & $p$ & HR & $95 \% \mathrm{CI}$ & $p$ \\
\hline Age, per year & 0.98 & $0.91-1.06$ & 0.67 & 1.02 & $0.91-1.14$ & 0.78 \\
\hline Gender, female vs. male & 4.86 & $0.88-26.95$ & 0.07 & 2.47 & $0.27-22.41$ & 0.42 \\
\hline Body mass index, per $\mathrm{kg} / \mathrm{m}^{2}$ & 0.90 & $0.69-1.17$ & 0.43 & 0.74 & $0.44-1.25$ & 0.26 \\
\hline Alcohol use, abuse vs. none/moderate & 0.76 & $0.20-2.89$ & 0.69 & 0.04 & $0-560.31$ & 0.50 \\
\hline Smoking habits, current vs. never/past & 0.81 & $0.18-3.69$ & 0.78 & 0.04 & $0-560.31$ & 0.50 \\
\hline Diabetes mellitus, yes vs. no & 3.47 & $0.39-31.11$ & 0.27 & 3.72 & $0.42-33.36$ & 0.24 \\
\hline Normal ALT ( $\leq 40 \mathrm{IU} / \mathrm{L})$, no vs. yes & 0.39 & $0.05-3.21$ & 0.38 & 0.33 & $0.03-3.69$ & 0.37 \\
\hline Platelet counts, per $10^{6} / \mathrm{mm}^{3}$ & 1.00 & $0.99-1.01$ & 0.37 & 1.00 & $0.99-1.01$ & 0.35 \\
\hline Undetectable HBV DNA, no vs. yes & 0.93 & $0.32-2.75$ & 0.90 & 0.01 & $0-16.43$ & 0.22 \\
\hline Alpha-fetoprotein, per ng/mL & 1.00 & $1.00-1.00$ & 0.11 & 1.00 & $1.00-1.00$ & 0.52 \\
\hline Cirrhosis, no vs. yes & 0.64 & $0.22-1.87$ & 0.42 & 0.01 & $0-18.09$ & 0.24 \\
\hline PAGE-B score, per unit & 0.84 & $0.69-1.03$ & 0.09 & 0.95 & $0.67-1.36$ & 0.79 \\
\hline BCLC stage & 1.04 & $0.42-2.57$ & 0.94 & 1.00 & $0.17-6.05$ & 1.00 \\
\hline cfDNA concentration, per ng/mL & 0.99 & $0.98-1.01$ & 0.27 & 1.01 & $0.99-1.02$ & 0.36 \\
\hline Alu115 levels, per GE & 0.99 & $0.98-1.00$ & 0.06 & 0.99 & $0.97-1.01$ & 0.28 \\
\hline Alu247 levels, per GE & 0.99 & $0.98-1.01$ & 0.07 & 0.99 & $0.98-1.01$ & 0.58 \\
\hline Alu247/ Alu115 ratio (DNA integrity), per unit & 2.16 & $1.02-4.61$ & 0.06 & 2.46 & $1.15-5.28$ & 0.02 \\
\hline Nucleosomes, per ng/mL & 0.98 & $0.96-1.01$ & 0.18 & 1.01 & $0.98-1.05$ & 0.44 \\
\hline
\end{tabular}




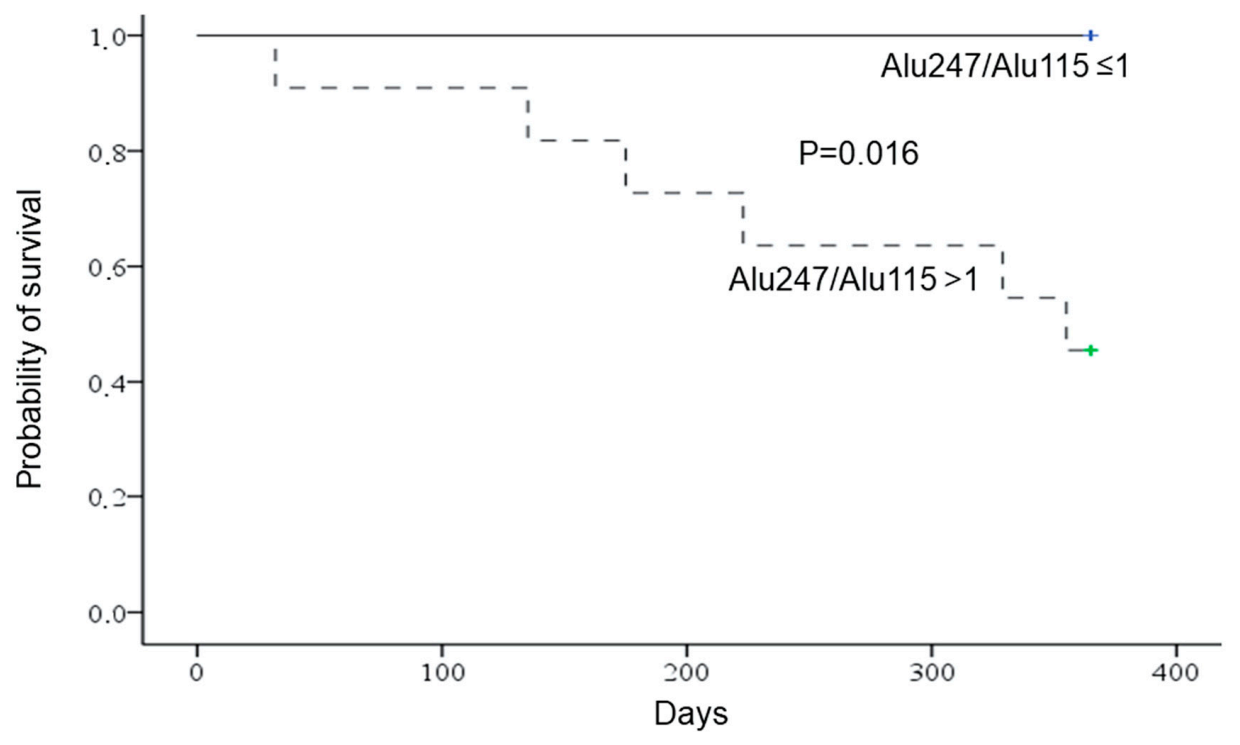

Figure 2. Probability of survival within the first year after diagnosis of hepatocellular carcinoma in 19 patients with chronic hepatitis B in relation to the presence of increased DNA integrity (Alu247/Alu115 ratio > 1). Log-rank test was used to assess statistical significance.

\section{Discussion}

Liquid biopsy biomarkers, including circulating cfDNA and nucleosomes, have been recently associated with inflammation and malignancies and seem to represent promising markers for both early detection and monitoring the response to treatment of several cancers $[8,17]$. This is the first study attempting to evaluate the significance of circulating biomarkers, such as cfDNA, its components, and nucleosomes in CHB patients with HCC. In particular, we hypothesized that quantitative and qualitative alterations in serum cfDNA or nucleosomes may be implicated in hepatocarcinogenesis in CHB patients and potentially affect the prognosis after HCC development.

Our major finding was that DNA integrity, expressed as the ratio of longer DNA fragments to shorter DNA fragments (Alu247/Alu115), was higher, and increased DNA integrity (Alu247 / Alu115 > 1) was more frequently observed in CHB patients with HCC compared to $\mathrm{CHB}$ patients without HCC during $\geq 5$ years of follow-up in patients receiving therapy who were carefully matched for known HCC risk factors. Higher DNA integrity has been previously associated with several malignancies [14,15]. Interestingly, increased DNA integrity of cfDNA was associated with a higher risk of death during the first year after HCC diagnosis, although it was not associated with overall survival. DNA integrity has previously been associated with advanced tumor stages and poorer prognosis $[18,19]$. The association of increased DNA integrity with worse one-year overall survival in our HCC cases could be due to its association with an extensive disease burden and therefore worse short-term mortality. On the other hand, the overall mortality of HCC cases may be also affected by the efficacy of several therapeutic interventions, which is not expected to be associated with any cfDNA marker. In our study, the BCLC stage was not associated with patients' overall survival. This could be attributed to the fact that our patients were almost exclusively classified as stage B.

Serum levels of the Alu247 element were higher in our HCC cases compared to matched CHB controls. Such a finding is in agreement with findings in patients with other malignancies who have been reported to have longer circulating Alu sequences of cfDNA more frequently compared to healthy individuals $[14,15]$. Circulating cfDNA consists of both coding and non-coding elements, including transposable repeated sequences, such as Alu repeats [11], and cancer is frequently related to a state of necrotic inflammation leading to a vast release of DNA fragments in the circulation $[13,15]$. 
Recent studies have demonstrated raised concentrations of serum cfDNA in patients with cancer $[10,12,20]$. In our study, however, there was no difference in the serum levels of cfDNA, as indicated by the housekeeping gene GAPDH and the short Alu repeat of $115 \mathrm{bp}$ between HCC cases and CHB controls. In addition, these biomarkers were not associated with either the overall or one-year mortality of our HCC cases. Of note, both our HCC cases and controls suffered from $\mathrm{CHB}$, which represents a chronic inflammatory hepatic disease, and as such, it is related to excessive release of DNA fragments in the bloodstream from non-cancerous hepatocytes [21].

Interestingly, circulating nucleosomes did not differ between our CHB patients with and without HCC. Nucleosomes were previously related to tumor detection and monitoring treatment response in oncology [17]. Our findings may be at least partially explained by the fact that circulating nucleosomes can be elevated in CHB irrespectively of HCC [21], while their levels may not increase further in CHB patients who develop HCC.

Our study was based on a homogeneous population of Caucasian patients with HBeAg-negative $\mathrm{CHB}$, including cases with confirmed $\mathrm{HCC}$ and carefully matched controls who did not develop HCC for $\geq 5$ years of follow-up. However, it has some limitations. Since all our patients were Caucasians, our results cannot be generalized in Asian CHB patients, in whom the pathogenesis of HCC may be different. Most importantly, it was a single-center study with a relatively limited number of participants, which prevented us from definitely excluding type II errors. In addition, we included HCC cases mostly of the intermediate stage (BCLC B), and thus our results need to be assessed in larger numbers of HCC cases of various stages. Therefore, further cohorts with larger sample sizes are required to validate our findings.

\section{Materials and Methods}

\subsection{Patient Population}

In total, 57 Caucasian adult patients with HBeAg-negative CHB were included. All patients were followed up at the outpatient liver clinics of the General Hospital of Athens "Laiko" over the last 5 years. In particular, 19 consecutive such patients who developed HCC were included (HCC cases) if they had available stored serum samples drawn within the first month after HCC diagnosis. Subsequently, another 38 matched CHB patients who did not develop HCC during $\geq 5$ years of therapy with entecavir (ETV) or tenofovir disoproxil fumarate (TDF) were included (CHB controls) if they had an available serum sample drawn before ETV/TDF onset. CHB controls were selected at a 2:1 ratio with HCC cases after matching for the following main HCC risk factors in Caucasian, treated CHB patients: age ( \pm 5 years), gender, and platelet group $\left(<100,000,100,000-199,999, \geq 200,00 / \mathrm{mm}^{3}\right)$ [22] . Exclusion criteria for both HCC cases and CHB controls included decompensated cirrhosis; coinfection(s) with hepatitis D, hepatitis C, or human immunodeficiency virus, and a history of liver transplantation. Informed consent was obtained from all patients for the anonymous use of their data and biological material. The study protocol was approved by the university ethics committee.

\subsection{Definitions and Follow-Up}

HBeAg-negative CHB was diagnosed in patients who had positive HBsAg and negative HBeAg for $\geq 6$ months, elevated ALT levels on $\geq 2$ monthly occasions, and serum HBV DNA > $2000 \mathrm{IU} / \mathrm{mL}$. The severity of liver disease was determined before the onset of ETV/TDF. Only CHB without cirrhosis was diagnosed by compatible liver histological lesions, while CHB with cirrhosis (always compensated) was diagnosed by compatible histological, ultrasonographic, and/or endoscopic findings. In particular, the diagnosis of cirrhosis was based on histological findings in 20 of the 24 cirrhotic patients (8 with HCC and 12 controls) and on ultrasonographic (nodular liver parenchyma) and endoscopic (esophageal varices) findings in the remaining four patients. The HCC diagnosis was based on standard histological and/or imaging findings [1]. 
All CHB controls were followed according to the national guidelines. Physical examination and laboratory routine tests including, hematological and biochemical parameters, were obtained every 3-6 months. Serum HBV DNA levels were determined every 6-12 months. HCC surveillance was based on 6-monthly ultrasound imaging. HCC stage was diagnosed according to BCLC staging classification [1].

\subsection{Laboratory Analysis}

Serum samples were stored in polypropylene tubes at $-80{ }^{\circ} \mathrm{C}$ until our analysis. All samples were collected within the first month after HCC diagnosis but before any treatment for HCC in HCC cases and before the onset of ETV/TDF in CHB controls. Some of our $\mathrm{CHB}$ controls were also included in a previous study by our group [23], in which, however, different serum samples at ETV/TDF onset were analyzed.

The Plasma/Serum Cell-Free Circulating DNA Purification Mini Kit (cat. no. 55100) (Norgen Biotek. Corporation, Thorold, ON, Canada) was used to isolate circulating cfDNA from $200 \mu \mathrm{L}$ serum samples [24]. For each sample, the concentration of the extracted cfDNA was measured by quantitative real-time polymerase chain reaction (RT-PCR) assay for the GAPDH housekeeping gene. The relevant primers used were GAPDHf: $5^{\prime}-$ GGAAGGTGAAGGTCGGAGTC-3 and GAPDHr: 5'-GAAGATGGTGATGGGATTTC-3 [19,21]. All samples were analyzed in duplicate. The final value used was the mean of the two measurements.

The genomic equivalents (GE) of Alu115 and Alu247 repeats were assessed by quantitative RT-PCR. The relevant primers were 5-GGAGGCTGAGGCAGGAGAA-3 and 5ATCTCGGCTCACTGCAA CCT-3 for Alu115 as well as 5-CAAGACTTAGTACCTGAAGGG TGAA-3 and 5-CTTGCCTCTTTCCTAGCACTG-3 for Alu247, as forward and reverse, respectively $[11,23]$.

TaqMan Control Genomic DNA (Applied Biosystems ${ }^{\mathrm{TM}}$ cat. no. 4312660) (human) was used to obtain the standard curve of cfDNA concentration and assess the GE of Alu115 and Alu247. One GE was considered equal to $3.3 \mathrm{pg}$ of human genomic DNA [25].

BIORAD iQ5 with 45 cycles of amplification under standard cycling conditions (950 C for $1 \mathrm{~min}, 950 \mathrm{C}$ for $3 \mathrm{~s}$, and $600 \mathrm{C}$ for $30 \mathrm{~s}$ ) was used in order to conduct the quantitative PCR assays. Data collection and real-time analysis were enabled at $65{ }^{\circ} \mathrm{C}-95^{\circ} \mathrm{C}$ for $30 \mathrm{~s}$.

The master mix that was used for PCR assays was Kapa SYBR Fast qPCR Master Mix (Kapa Biosystem cat. no. KK 4608).

Serum nucleosomes levels were measured by Cell Death Detection ELISA ${ }^{\text {PLUS }}$ (Roche Diagnostics, Burgess Hill, UK, cat. no. 11774425001) following the manufacturer's instructions [26]. The results are expressed relative to controls, arbitrary units, or ng $/ \mathrm{mL}$.

\subsection{Statistical Analysis}

Statistical analyses were performed using SPSS (SPSS 26, IBM company, Chicago, IL, USA, 2019). All quantitative variables were presented as median values (interquartile range (IQR)). Quantitative variable comparisons between two groups were performed using the non-parametric Mann-Whitney test. The associations between quantitative variables were assessed by Spearman's correlation and expressed by Spearman's coefficient (r). Categorical variables were summarized as frequencies and percentages, and their associations were determined using the corrected chi-squared or two-sided Fisher's exact test. Cumulative probabilities of HCC occurrence were estimated by Kaplan-Meier and compared using the log-rank test. To identify prognostic HCC risk factors, univariable and multivariable Cox proportional hazards models were used, and HRs with 95\% CIs and $p$ values were provided. Statistical significance was set at $p<0.05$.

\section{Conclusions}

In conclusion, our case control study presents a novel understanding of the significance of serum circulating biomarkers in CHB-induced HCC. In particular, elevated levels of the element Alu247 and higher DNA integrity were observed in CHB patients who developed 
HCC than in CHB patients who did not develop HCC during $\geq 5$ years of oral antiviral therapy with ETV or TDF.

Author Contributions: Conceptualization, A.C. and G.V.P.; data curation, A.P. and N.K.; formal analysis, N.K.; funding acquisition, A.C. and G.V.P.; investigation, A.P.; methodology, A.P., N.K., P.L. and G.V.P.; project administration, A.C.; resources, P.L.; software, A.P.; supervision, A.C.; validation, A.P., N.K. and G.V.P.; visualization, G.V.P.; writing—original draft, A.P. and N.K.; writing-review and editing, P.L., A.C. and G.V.P. All authors have read and agreed to the published version of the manuscript.

Funding: This work was supported by an unrestricted research grant from Gilead Sciences and by the Hellenic Foundation of Gastroenterology and Nutrition.

Institutional Review Board Statement: The study was conducted according to the guidelines of the Declaration of Helsinki and approved by the Ethics Committee of the National and Kapodistrian University of Athens.

Informed Consent Statement: Informed consent was obtained from all subjects involved in the study.

Data Availability Statement: Data available upon request.

Conflicts of Interest: G.V.P. has served as advisor and/or lecturer for Abbvie, Dicerna, Gilead, GlaxoSmithKline, Ipsen, Janssen, Merck Sharp \& Dohme, Novo Nordisk, Roche, Takeda and has received research grants from Abbvie and Gilead. The other authors declare no conflict of interest.

\section{References}

1. Galle, P.R.; Forner, A.; Llovet, J.M.; Mazzaferro, V.; Piscaglia, F.; Raoul, J.-L.; Schirmacher, P.; Vilgrain, V. EASL Clinical Practice Guidelines: Management of hepatocellular carcinoma. J. Hepatol. 2018, 69, 182-236. [CrossRef]

2. Lampertico, P.; Agarwal, K.; Berg, T.; Buti, M.; Janssen, H.L.A.; Papatheodoridis, G.; Zoulim, F.; Tacke, F. EASL 2017 Clinical Practice Guidelines on the management of hepatitis B virus infection. J. Hepatol. 2017, 67, 370-398. [CrossRef] [PubMed]

3. Papatheodoridis, G.V.; Sypsa, V.; Dalekos, G.; Yurdaydin, C.; van Boemmel, F.; Buti, M.; Goulis, J.; Calleja, J.-L.; Chi, H.; Manolakopoulos, S.; et al. Eight-year survival in chronic hepatitis B patients under long-term entecavir or tenofovir therapy is similar to the general population. J. Hepatol. 2018, 68, 1129-1136. [CrossRef] [PubMed]

4. Terrault, N.A.; Lok, A.; McMahon, B.J.; Chang, K.M.; Hwang, J.P.; Jonas, M.M.; Brown, R.S., Jr;; Bzowej, N.H.; Wong, J.B. Update on prevention, diagnosis, and treatment of chronic hepatitis B: AASLD 2018 hepatitis B guidance. Hepatology 2018, 67, 1560-1599. [CrossRef] [PubMed]

5. Papatheodoridis, G.V.; Chan, H.L.; Hansen, B.E.; Janssen, H.L.A.; Lampertico, P. Risk of hepatocellular carcinoma in chronic hepatitis B: Assessment and modification with current antiviral therapy. J. Hepatol. 2015, 62, 956-967. [CrossRef] [PubMed]

6. Papatheodoridis, G.V.; Lampertico, P.; Manolakopoulos, S.; Lok, A. Incidence of hepatocellular carcinoma in chronic hepatitis B patients receiving nucleos(t)ide therapy: A systematic review. J. Hepatol. 2010, 53, 348-356. [CrossRef] [PubMed]

7. Volik, S.; Alcaide, M.; Morin, R.D.; Collins, C. Cell-free DNA (cfDNA): Clinical significance and utility in cancer shaped by emerging technologies. Mol. Cancer Res. 2016, 14, 898-908. [CrossRef] [PubMed]

8. Wan, J.C.M.; Massie, C.; Garcia-Corbacho, J.; Mouliere, F.; Brenton, J.D.; Caldas, C.; Pacey, S.; Baird, R.; Rosenfeld, N. Liquid biopsies come of age: Towards implementation of circulating tumour DNA. Nat. Rev. Cancer 2017, 17, 223-238. [CrossRef]

9. Tomochika, S.; Iizuka, N.; Watanabe, Y.; Tsutsui, M.; Takeda, S.; Yoshino, S.; Ichihara, K.; Oka, M. Elevated levels of circulating cellfree DNA in the blood of patients with hepatitis $C$ virus-associated hepatocellular carcinoma. Anticancer Res. 2006, 26, 4713-4719.

10. Fleischhacker, M.; Schmidt, B. Circulating nucleic acids (CNAs) and cancer-A survey. Biochim. Biophys. Acta 2007, 1775, 181-232. [CrossRef]

11. Jylhava, J.; Nevalainen, T.; Marttila, S.; Jylha, M.; Hervonen, A.; Hurme, M. Characterization of the role of distinct plasma cell-free DNA species in age-associated inflammation and frailty. Aging Cell 2013, 12, 388-397. [CrossRef] [PubMed]

12. Hao, T.B.; Shi, W.; Shen, X.J.; Qi, J.; Wu, X.H.; Wu, Y.; Tang, Y.Y.; Ju, S.Q. Circulating cell-free DNA in serum as a biomarker for diagnosis and prognostic prediction of colorectal cancer. Br. J. Cancer 2014, 111, 1482-1489. [CrossRef] [PubMed]

13. Jahr, S.; Hentze, H.; Englisch, S.; Hardt, D.; Fackelmayer, F.O.; Hesch, R.D.; Knippers, R. DNA fragments in the blood plasma of cancer patients: Quantitations and evidence for their origin from apoptotic and necrotic cells. Cancer Res. 2001, 61, 1659-1665.

14. Zhang, R.; Pu, W.; Zhang, S.; Chen, L.; Zhu, W.; Xiao, L.; Xing, C.; Li, K. Clinical value of ALU concentration and integrity index for the early diagnosis of ovarian cancer: A retrospective cohort trial. PLoS ONE 2018, 13, e0191756. [CrossRef] [PubMed]

15. Hussein, N.A.; Mohamed, S.N.; Ahmed, M.A. Plasma ALU-247, ALU-115, and cfDNA integrity as diagnostic and prognostic biomarkers for breast cancer. Appl. Biochem. Biotechnol. 2019, 187, 1028-1045. [CrossRef]

16. Holdenrieder, S.; Nagel, D.; Schalhorn, A.; Heinemann, V.; Wilkowski, R.; von Pawel, J.; Raith, H.; Feldmann, K.; Kremer, A.E.; Müller, S.; et al. Clinical relevance of circulating nucleosomes in cancer. Ann. N. Y. Acad. Sci. 2008, 1137, 180-189. [CrossRef] 
17. McAnena, P.; Brown, J.A.L.; Kerin, M.J. Circulating nucleosomes and nucleosome modifications as biomarkers in cancer. Cancers 2017, 9, 5. [CrossRef]

18. Chudasama, D.Y.; Aladag, Z.; Felicien, M.I.; Hall, M.; Beeson, J.; Asadi, N.; Gidron, Y.; Karteris, E.; Anikin, V.B. Prognostic value of the DNA integrity index in patients with malignant lung tumors. Oncotarget 2018, 9, 21281-21288. [CrossRef]

19. El-Shazly, S.F.; Eid, M.A.; El-Sourogy, H.A.; Attia, G.F.; Ezzat, S.A. Evaluation of serum DNA integrity as a screening and prognostic tool in patients with hepatitis C virus-related hepatocellular carcinoma. Int. J. Biol. Markers 2010, 25, 79-86. [CrossRef]

20. Gong, B.; Xue, J.; Yu, J.; Li, H.; Hu, H.; Yen, H.; Hu, J.; Dong, Q.; Chen, F. Cell-free DNA in blood is a potential diagnostic biomarker of breast cancer. Oncol. Lett. 2012, 3, 897-900. [CrossRef]

21. Campion, D.; Tucci, A.; Ponzo, P.; Caviglia, G.P. Non-invasive biomarkers for the detection of hepatocellular carcinoma. Minerva Biotech. 2019, 31, 11-22. [CrossRef]

22. Papatheodoridis, G.; Dalekos, G.; Sypsa, V.; Yurdaydin, C.; Buti, M.; Goulis, J.; Calleja, J.L.; Chi, H.; Manolakopoulos, S.; Mangia, G.; et al. PAGE-B predicts the risk of developing hepatocellular carcinoma in Caucasians with chronic hepatitis B on 5-year antiviral therapy. J. Hepatol. 2016, 64, 800-806. [CrossRef]

23. Papatheodoridi, A.; Chatzigeorgiou, A.; Chrysavgis, L.; Lembessis, P.; Loglio, A.; Facchetti, F.; Cholongitas, E.; Koutsilieris, M.; Lampertico, P.; Papatheodoridis, G. Circulating cell-free DNA species affect the risk of hepatocellular carcinoma in treated chronic hepatitis B patients. J. Viral Hepat. 2021, 28, 464-474. [CrossRef] [PubMed]

24. Kirov, A.; Mihaylova, Z.; Petrova, V.; Todorov, T.; Petkova, D.; Garev, A.; Todorova-Georgieva, A. KRAS-dependent and independent mechanisms of progressive disease (PD) in colorectal cancer (CRC) patients (pts) with liver metastases (LM) while monitoring on circulating cell free DNA (cfDNA). Ann. Oncol. 2018, 29, viii185. [CrossRef]

25. Diehl, F.; Schmidt, K.; Choti, M.A.; Romans, K.; Goodman, S.; Li, M.; Thornton, K.; Agrawal, N.; Sokoll, L.; Szabo, S.A.; et al. Circulating mutant DNA to assess tumor dynamics. Nat. Med. 2008, 14, 985-990. [CrossRef] [PubMed]

26. Fahmueller, Y.N.; Nagel, D.; Hoffmann, R.T.; Tatsch, K.; Jakobs, T.; Stieber, P.; Holdenrieder, S. Predictive and prognostic value of circulating nucleosomes and serum biomarkers in patients with metastasized colorectal cancer undergoing selective internal radiation therapy. BMC Cancer 2012, 12, 5. [CrossRef] [PubMed] 